Research Paper

\title{
The Relationship between Leadership Behaviors of University Middle-level Managers and Faculty Engagement
}

\author{
Yu Sing ONG \\ Corresponding author: victor.yu@help.edu.my \\ HELP University, Malaysia \\ JIANG YAQIONG \\ Guilin University of Electronic Technology \\ Guangxi, China
}

\section{About the authors}

Yu Sing Ong holds a Ph.D. in Business, Ph.D. in Arts, Master in Design, Master in Business Administration, and a Bachelor of Science. He is also a Certified Financial Planner in Malaysia. He has over 30 years of senior management experience in banking, research, consulting and education. He started his career in Wall Street, New York, in the 1980s. Following his return to Singapore, he was instrumental in establishing the Investment Management unit of a major pension fund. He was also the Research Director of a major bank in Singapore, Malaysia and Indonesia and the Regional Vice President of an international investment bank. He has provided consultancy services to over 500 private and public companies and government agencies in ASEAN. As an academician, he has held senior academic and administrative roles at different private institutions in Singapore, Malaysia and Vietnam. He is the author of three books on Education Management, Oriental Management and Islamic Management.

Jiang Yaqiong holds a Master degree in Engineering from Guilin University of Electronic Technology, China and a Bachelor of Technology from Tianjin University of Technology, China. She is currently the director of Information and Network Education at Centre of Educational Technology, Guilin University of Electronic Technology. She is also a doctoral candidate at HELP University. 


\section{Abstract}

This study investigated the relationship between leadership behaviors of middle-level managers and faculty engagement. Faculty engagement is emerging as a critical organizational issue, especially for China's universities as the country is pushing its universities towards achieving world-class status. Leadership behaviors play an important part in faculty engagement as in the case of the two Chinese public universities in our study. University middle-level managers have to work hard to engage others in the organization, particularly those in the faculty. Having an engaged faculty reaps many benefits for the universities as they seek to increases their overall organizational performance. Middle-level managers must communicate their values in both behaviors and actions. The data collected in this study were analyzed using structural equation modeling.

Keywords:University leadership behavior, Faculty engagement, Character, Performance, Moral

\section{Introduction}

The relationships between university and government, university and society, and university and marketplace have changed radically over the last two decades. Faculty members are the most important human resource of the university, and their behaviors and performance will have significant impacts on university performance. The same applies to members from other types of organizations as work engagement is deemed to increase work efficiency of members and integral efficiency of the organization (Anitha, 2014; Harter, Schmidt and Hayes, 2002). The success of universities depends largely on their faculties. The active engagement of faculty members will help to improve the quality of the universities. Faculty members who work directly to advance the institutional mission of teaching, learning, and research represent the core human resource of higher education. The success of university depends greatly on engaged faculty members and strong academic team cohesion that deliver quality education and meeting the needs and expectations of students. Faculty work engagement and academic team cohesion are closely related to the competitiveness of universities (Wang and Hsieh, 2013).

In recent years, with the rapid development of China's higher education, the gross enrollment rate of students into colleges and universities have improved significantly from $12.5 \%$ in 2002 to $48 \%$ in 2016 (UNESCO, 2016). The number of Chinese universities and colleges has also increased from 1,041 in 2000 to 2,914 in 2017 (MOE, China, 2018). The number of universities in China accounts for about $11 \%$ of the total number of universities in the world, second only to the United States which has 4,724 degree granting institutions in 2014 (US Department of Education, 2016).

The rapid development of China's higher education has also resulted in new challenges such as faculty's career burnout, low engagement, and low team cohesion. Low level of work engagement of faculty will not only affect the quality of education and teaching but will also result in the decline or even loss of core competitiveness of universities. 
It is a challenge to maintain the quality of education as China seeks to promote the massification of higher education. In 2016, the Chinese Academy of Educational Sciences conducted a survey on higher education satisfaction in 31 provinces. A total of 448,000 students from 350 universities took part in the survey. The survey results showed that the overall satisfaction index of China's higher education is not high, and some of the answers revealed the poor professional spirit of faculty members. This is especially worrying as China seeks to improve its higher education standing in the world. In October 2015, the Chinese government announced an initiative to develop 42 world-class universities and first-class disciplines. The plan of "double first-class" (world-class universities and first-class disciplines among the world's best) is an updated version of the 985 and 211 projects. The initiative calls for the development of first-class teachers and developing innovative and interdisciplinary teams while strengthening traditional Chinese culture and socialist values in Chinese universities. In order to achieve this ambitious plan, universities need more engaged faculty members. Faculty work engagement is the key determining the quality of teaching and long-term development of China's public universities. It is imperative for China's universities to improve the level of teaching and research, upgrade the quality of education, and cultivate high-quality talent through active faculty engagement.

This research will investigate the role university middle-level managers' behavior plays in the promotion of faculty work engagement. The authors have developed a methodological framework to investigate the relationship between middle-level managers' leadership behavior and faculty work engagement in two public universities. The effectiveness of the managers will be enhanced if they could manage to integrate faculty engagement into the university's human capital strategies.

\section{Literature review}

Leaders' behaviors have a direct impact on subordinates' working attitude, satisfaction, and loyalty. It affects the level of engagement the leader has with his or her subordinates. Previous studies have found that transformational leadership and paternalistic leadership behaviors have significant impacts on employee engagement (Breevaart, Bakker, Hetland et. al, 2014; Mencl, Wefald and van Ittersum, 2016; Vincent-Höper, Muser and Janneck, 2012).

Leadership behavior is an essential element influencing subordinates' psychological needs and emotions. Leaders affect the features of tasks and work designs, which are regarded as crucial elements of motivating work engagement (Gagne and Deci, 2014). According to the Performance Maintenance Leadership theory (Misumi, and Peterson, 1985), it is necessary to evaluate the effectiveness of leaders from the following two perspectives: first, the performance of the leader in achieving the aim of the organization (P-oriented); second, the maintenance of the relationship of group members in the organization (M-oriented). P-oriented refers to the function of planning, organizing, coordinating and managing adopted by the leader to achieve organizational performance goals. M-oriented refers to the role of team maintenance adopted by the leader to preserve group social stability.

Chinese leadership behaviors have many significant differences from that of the West due to cultural 
differences. In traditional Chinese culture, a qualified leader needs to have two fundamental qualities: moral and ability. Morality is the first requirement when selecting someone for a leadership position in China. Ling, Chen and Wang (1987) evaluated the effectiveness of leaders in Chinese context by adding Character and Moral dimension (C-oriented) to establish the CPM three-dimensional model, an extension of the Performance Maintenance model of Misumi and Peterson (1985). The C factor refers to the leader's personal characteristics such as his moral values, ethical beliefs, integrity, fairness, justice, selflessness, honesty, and trustworthiness. An active leader, in theory, would not only be able to prevent job stress and burnout among faculty members, but would also be successful in motivating and engaging his subordinates.

Moral leadership behaviors help to improve employees' sense of effectiveness and satisfaction as well as facilitate their involvement (Huang and $\mathrm{Su}, 2016$ ). The ethical behavior of the leader creates a conducive environment which motivates employees to work harder (Ehrhart, 2004). Scholars have noted that transformational leadership is positively related to employee engagement. Through social cognition, the moral behavior of the leader has an influence on the members of the organization (Lu and Lin, 2014) and on their loyalty, engagement and job satisfaction (Ling and Ling, 2010; Meng and Han, 2014).

According to PM leadership theory, the consequences of leadership in Japan are the result of the interaction of P-oriented and M-oriented behaviors (Misumi and Peterson, 1985). Their findings indicated that leadership at the middle and lower management levels may be more important for subordinates' performance in Japan than in the United States. According to the expectancy concept, the intensity of an individual to perform in a particular manner is dependent on the intensity of the expectation that the performance will be followed by the desired outcome. Leaders' P-oriented behaviors such as allocating clear tasks to subordinates, recognizing their job performance and giving them guidance have an impact on subordinates' beliefs that they have achieved specific goals.

The third component of the PM leadership theory, M-oriented behaviors refer to the function of team maintenance adopted by the leader in order to achieve organizational performance, including motivation, care, support, trust and respect their subordinates. Leaders who are able to provide support and build an environment of trust were able to increase employee work engagement. They can influence the level of employee engagement by sharing information with subordinates and involving them in decision-making (Albrecht and Andreetta, 2011). The trust and empowerment of subordinates will motivate them to be more dedicated to their work.

Employee engagement can be defined as "a positive, fulfilling, and work-related state of mind that is characterized by vigor, dedication, and absorption" (Schaufeli, Salanova, Gonzalez-Roma and Bakker, 2002). The active engagement of faculty has a direct impact on the quality of China's higher education and the development of colleges and universities. McKinney (2004) noted that with an engaged and enthusiastic faculty, the university will be able to achieve the goal of scientific research and personnel development more easily.

Robinson, Perryman and Hayday (2004) noted that factors influencing the development of employee engagement are mainly manifested in five aspects: 1) the employee feeling valued and involved; 2) cooperation and interpersonal relationship; 3) communication; 4) training, development and career; and 5) equal oppor- 
tunities and fair treatment. These five aspects have significant correlations with leadership behaviors. Other factors which could positively influence employee engagement include the trust that management showed in its employees and the interpersonal relationships between co-workers. An effective leader would not only be able to prevent job stress and burnout among faculty members but would also be able to engage them actively.

\section{Research Objective}

The purpose of this paper is to study the impact of leadership behavior on faculty engagement. The findings of this study will help policymakers and top management of higher education institutions to better engage faculty members to maximize their performances.

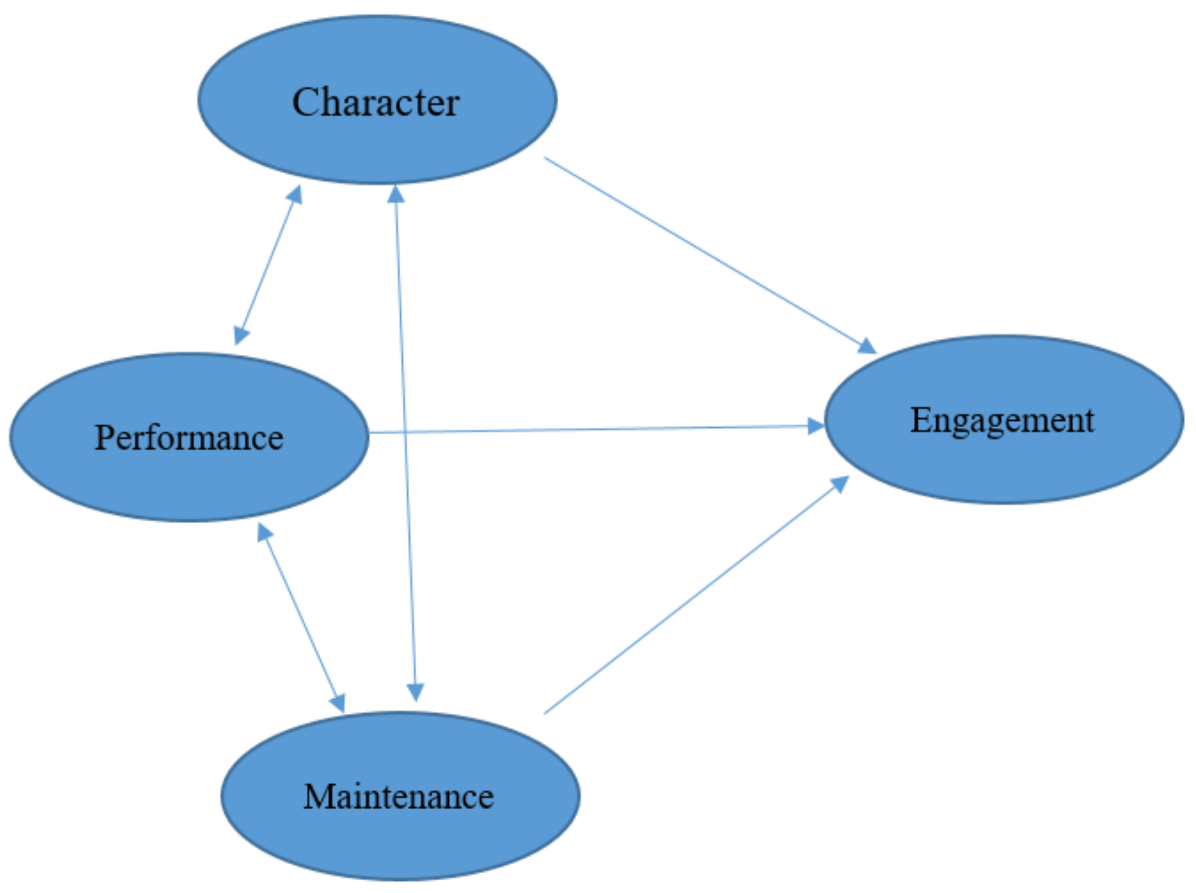

Fig. 1 CPM - Engagement Framework

\section{Hypotheses Development}

H1: University middle level managers' character and morals (C-oriented) dimension have a significant relationship with faculty work engagement.

H2: University middle-level managers' performance (P-oriented) dimension has a significant relationship with faculty work engagement.

H3: University middle-level managers' maintenance (M-oriented) dimension has a significant relationship with faculty work engagement. 


\section{Methodology}

\section{Participants}

The 116 sample consisted of 60 females (51.7 percent) and 56 males (48.3 percent). The education level of respondents was as follows: Bachelor's Degree (14.7 percent), Master's Degree (63.8 percent), and Doctoral Degree (21.6 percent). The respondents included assistant lecturers (4.3 percent), lecturers (48.3 percent), assistant professors (33.6 percent), professors (7.8 percent), and others (6 percent).

\section{The instrument}

A cross-sectional quantitative research design was used to obtain survey data to investigate the impact of university middle level managers' behavior on faculty work engagement. The data was collected through self-administered online questionnaire from two public universities in Guilin, China. A total of 125 surveys were distributed, yielding a response rate of $93 \%$.

There were two questionnaires for this study: the Character Maintenance Performance (CMP) Scale (Ling, Chen and Wang, 1987) and the Utrecht Work Engagement Scale (UWES) (Schaufeli and Bakker, 2003). The CMP questionnaire was used to measure the university middle level managers' leadership behavior present in the respective organizations of the participants involved in this study. Leadership behavior was investigated from the perception of faculty. The participants responded to how much leadership behavior affected them. Statements about leadership were provided through a 5-point Likert-type scale. UWES was used to measure the level of faculty engagement in the two universities as it is the most adopted measure of employee engagement by academic scholars (Christian, Garza and Slaughter, 2011). An engaged employee has a strong sense of vigor towards work, shows dedication and absorption in work activities.

We assessed the hypothesized model with SPSS and structural equation modeling technique using AMOS.

\section{Results and Discussions}

\section{SEM Analysis}

We use multiple indices of fit including the Root Mean Square Error of Approximation (RMSEA), (Goodness of Fit Index) GFI and Comparative Fit Index (CFI) to evaluate the model's fit to the empirical data.

The Good of Fit Index (GFI) was created as an alternative to the Chi-Square Test (Joreskog and Sorbom, 1984). It tells us what proportion of the variance in the sample variance-covariance matrix is accounted for by the model. A cut-off point of 0.90 had been recommended for the index. From Table出, the reading showed that there was a marginal fit.

The Comparative Fit Index (CFI) assumes that the latent variables were uncorrelated (Byrne, 1998). A standard value of CFI greater than 0.9 indicates a good fit. This index was least affected by sample size. As 
Table 1 Fitting Effect of the Model

\begin{tabular}{|c|c|c|c|}
\hline Index & RMSEA & GFI & CFI \\
\hline Value & 0.097 & 0.633 & 0.877 \\
\hline Standard & $<0.1$ & $>0.9$ & $>0.9$ \\
\hline Information & Good & Marginal & Good \\
\hline
\end{tabular}

Table 2 Hypotheses Tests

\begin{tabular}{|c|c|c|c|c|c|}
\hline & Estimates & S.E. & C.R. & P & Hypothesis \\
\hline Engagement $<$ - Character & 0.266 & .159 & 1.673 & .094 & Supported \\
\hline Engagement $<$ - Performance & 0.180 & .190 & 0.946 & .946 & Supported \\
\hline Engagement $<$ - Maintenance & 0.042 & .203 & 0.205 & .837 & Supported \\
\hline
\end{tabular}

the reading in TableW indicated a value close to 0.9, there was a good fit for CFI.

The Root Mean Square Error of Approximation (RMSEA) was developed by Steiger and Lind (1980). It gives an indication of how well the chosen parameter estimates would fit the population covariance matrix (Byrne, 1998). A value of less than 0.1 indicated a good fit (MacCallum, Browne and Sugawara, 1996). The reading in Table 1 showed a value close to 0.1, indicating a good fit for RMSEA.

\section{Hypothesis Test}

Table $\rrbracket$ shows the standardized regression weights for paths in the SEM model, along with standard errors, critical ratios and p-values.

- Hypothesis 1: Character has an impact on employee engagement.

The results from Table $\sqrt{2}$ showed that character had a positive effect on engagement (0.266). Based on Pearson correlation analysis, character had a positive impact on employees' sense of vigor with $\mathrm{r}$ values of between 0.38 and 0.551 , significant at the 0.01 level. Character also had a positive impact on employee dedication with $r$ values of between 0.379 and 0.433 . Similarly, there was a positive correlation between character and absorption in work activities with $\mathrm{r}$ values of between 0.305 and 0.515. Therefore, Hypothesis 1 is supported.

- Hypothesis 2: Performance has an impact on employee engagement.

The results in Table $\boldsymbol{\nabla}$ showed that Performance had a positive effect on engagement (0.18). The results of Pearson correlation analysis showed that Performance had a positive impact on employees' sense of vigor with $\mathrm{r}$ values of between 0.209 and 0.502 . Performance also showed a positive correlation with employee dedication with $r$ values of between 0.257 and 0.465. Similarly, Performance and absorption in work activities showed a positive correlation of between 0.252 and 0.495 , significant at the 0.01 
level. Therefore, Hypothesis 2 is supported.

- Hypothesis 3: Maintenance has an impact on employee engagement.

The results in Table $\nabla$ shows that Maintenance had a marginally positive effect on engagement (0.042). The results of Pearson correlation analysis showed that Maintenance had a positive impact on employees' sense of vigor with $\mathrm{r}$ values of between 0.205 and 0.475 . Maintenance also showed a positive correlation with employee dedication with $r$ values of between 0.271 and 0.453 . Similarly, Maintenance and absorption in work activities showed a positive correlation of between 0.225 and 0.430 , significant at the 0.01 level. Therefore, Hypothesis 3 is supported.

\section{Reliability Analysis}

From Table[1, Cronbach's alpha showed a reading of 0.973, which indicated a high level of internal consistency for our scale with this specific sample. The instrument can be deemed as reliable and valid.

The removal of any question would not result in a change in Cronbach's alpha, meaning that the responses to the questionnaire had been reliable. The "Corrected Item-Total Correlation" values for all the questions were above 0.595 , indicating a high degree to which one item correlates with the total scores from all the other items that remain.

Table 3 Reliability Statistics

\begin{tabular}{|c|c|c|}
\hline Cronbach's Alpha & Cronbach's Alpha Based on Standardized Items & N of Items \\
\hline .973 & .973 & 33 \\
\hline
\end{tabular}

\section{Principal Component Analysis}

We investigated the dimensionality of the scale using the Principal Component Analysis. SPSS extracted four factors. The first factor accounted for $53.74 \%$ of the total variance, the second factor $15.52 \%$, the third factor $3.49 \%$, and the fourth factor $3.23 \%$.

The small residuals in the reproduced matrix showed that there was very little difference between the reproduced correlations and the correlations actually observed between the variables. The rotated component matrix showed that vigor, dedication and absorption have positive loadings on the first factor. Character, Performance, and Maintenance all had high positive loadings on the second factor

The scree plot was used as an alternative criterion for determining the number of factors to retain after extraction. In this particular case, we retain the two components that were placed to the left of the point of inflection.

The result of the Kaiser-Meyer-Olkin showed a figure of 0.929 which indicated that the data was suitable for factor analysis. A value of 0.6 is a suggested minimum. The Bartlett's Test of Sphericity was significant as the associated probability was less than 0.05 . 
Table 4 Rotated Component Matrix

\begin{tabular}{|c|c|c|c|c|c|}
\hline \multicolumn{5}{|c|}{ Rotated Component Matrix } \\
\hline \multicolumn{3}{|c|}{ Components } & \multicolumn{3}{c|}{ Components } \\
\hline & 1 & 2 & & 1 & 2 \\
\hline C1 & 0.269 & 0.793 & V1 & 0.622 & 0.333 \\
C2 & 0.261 & 0.789 & V2 & 0.718 & 0.237 \\
C3 & 0.262 & 0.846 & V3 & 0.794 & 0.195 \\
C4 & 0.278 & 0.752 & V4 & 0.68 & 0.173 \\
C5 & 0.235 & 0.852 & V5 & 0.818 & 0.194 \\
C6 & 0.244 & 0.842 & V6 & 0.844 & 0.181 \\
P1 & 0.297 & 0.825 & D1 & 0.847 & 0.153 \\
P2 & 0.27 & 0.843 & D2 & 0.881 & 0.19 \\
P3 & 0.221 & 0.869 & D3 & 0.884 & 0.204 \\
P4 & 0.224 & 0.815 & D4 & 0.838 & 0.253 \\
P5 & 0.323 & 0.776 & D5 & 0.728 & 0.249 \\
M1 & 0.175 & 0.638 & A1 & 0.629 & 0.324 \\
M2 & 0.148 & 0.691 & A2 & 0.745 & 0.231 \\
M3 & 0.301 & 0.728 & A3 & 0.774 & 0.3 \\
M4 & 0.14 & 0.494 & A4 & 0.812 & 0.197 \\
M5 & 0.136 & 0.67 & A5 & 0.797 & 0.168 \\
\hline
\end{tabular}

Table 5 KMO and Bartlett's Test

\begin{tabular}{|l|c|c|}
\hline Kaiser-Meyer-Olkin Measure of Sampling Adequacy. & .929 \\
\hline Bartlett's Test of Sphericity & Approx. Chi-Square & 4145.049 \\
\cline { 2 - 3 } & df & 496 \\
\cline { 2 - 3 } & Sig. & .000 \\
\hline
\end{tabular}

\section{Recommendations}

The two universities in our study need to implement a Training Development Plan (TDP) to ensure that the middle-level managers have the required competencies to lead their faculties. The TDP is useful to map out one's career for further leadership development and succession planning within the faculty. Some of the core competencies which the middle-level managers need to achieve include job mastery and continuous learning, employee engagement, resource management, result orientation, teamwork and collaboration, innovation and change management, and people management (Fig. [3).

The authors recommend that each university create a Training Roadmap to assist the middle-level 


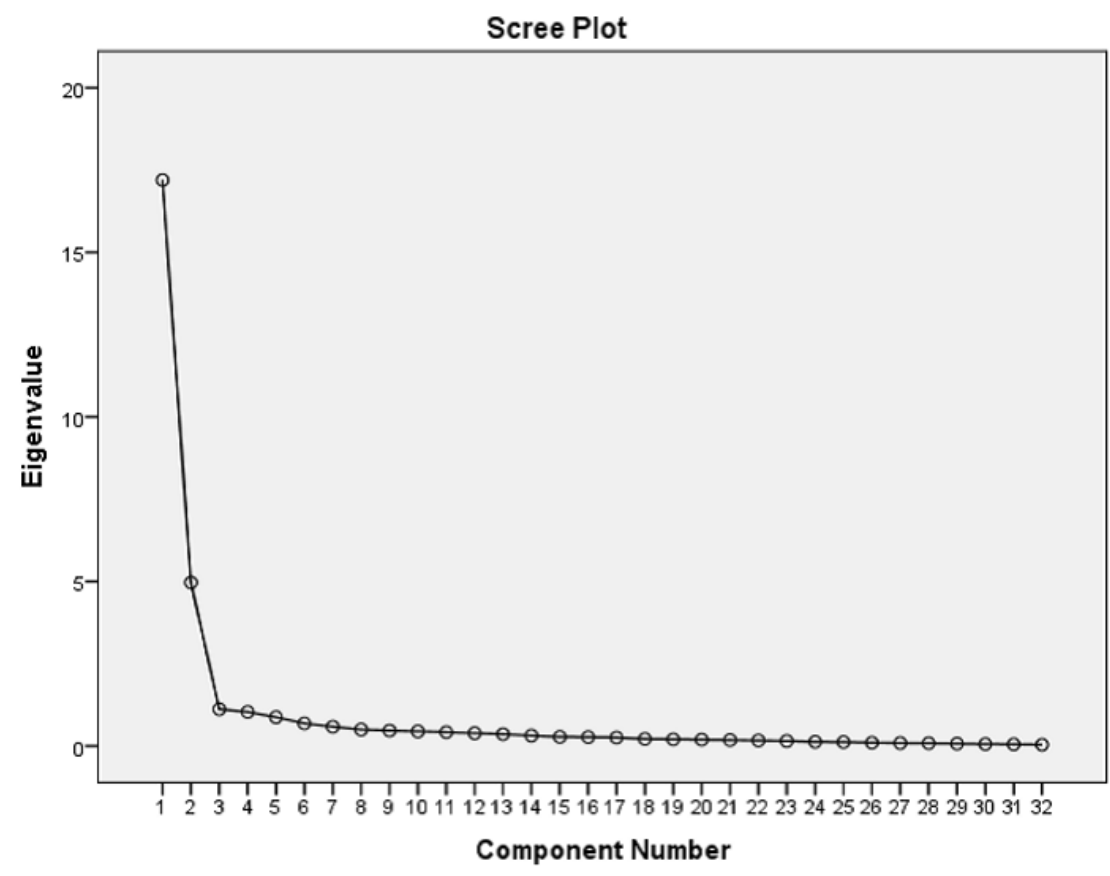

Fig. 2 Scree Plot

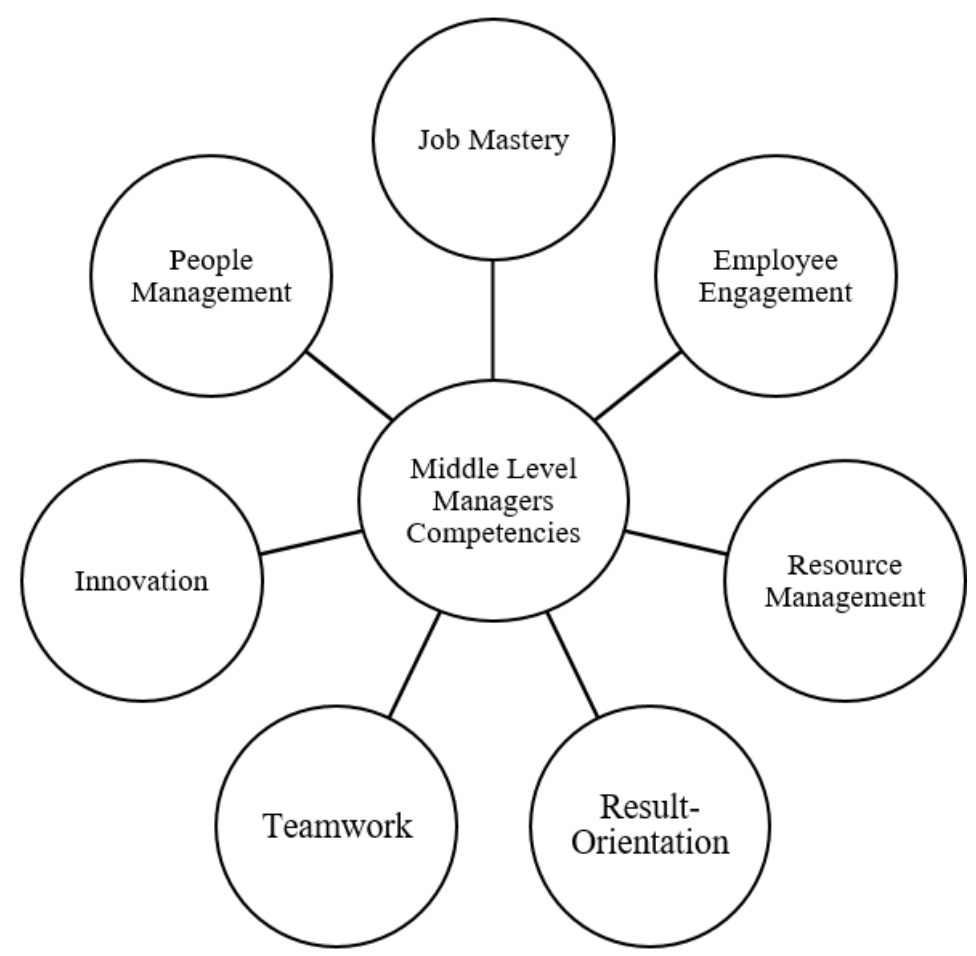

Fig. 3 Core Competencies

managers to further develop their managerial skills. Each phase of the roadmap must correspond to specific objectives to be achieved. The training topics must detail all the skills and knowledge that participants will gain at the end of each session. A generic training roadmap for the middle-level managers over a 12-month period is shown as in Fig. 四. 


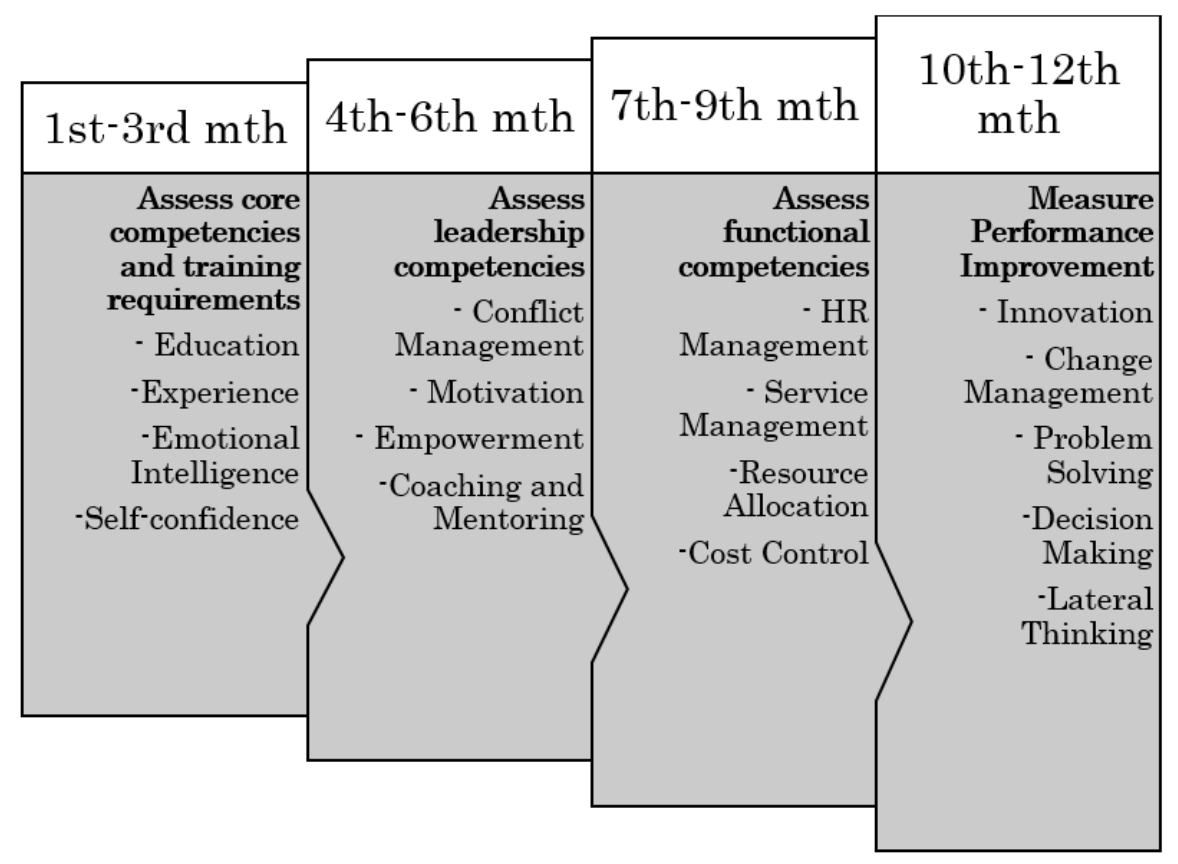

Fig. 4 Training Roadmap for Middle-level Managers

\section{Conclusion}

The results of this study confirmed that middle-level managers' behaviors had a direct effect on faculty engagement. Managers who consistently applied enablers of engagement were able to achieve higher team engagement. These included increasing subordinates degree of authority, decision-making, and accountability. The study has wide practical applications. Managers need to harness the concept of faculty engagement as a competitive strategy. The work experience of faculty is shaped by the cognitive perceptions and affective inferences stemming from interpersonal factors in the university. Managers who share information with team members and getting them involved in innovative projects will be able to facilitate an environment which supports the continuing professional development of the faculty, especially in the areas of new pedagogy and research. Faculty members with a strong sense of self-efficacy will likely try out new teaching styles and undertake more innovative research projects. University leaders have a duty to implement a comprehensive management training and development plan for middle-level managers to ensure that they have the necessary competencies to lead the faculties. All these will translate to higher student learning outcomes and faculty innovation. These outcomes are important as China's universities seek to improve the quality of education and achieve world-class status.

\section{Limitations}

This study had focused on two public universities in Guanxi Province, China, limiting the generalization of results. The authors recommend that the constructs used in this study be investigated in other public 
universities across China, employing a longitudinal design. It would be beneficial to examine other factors that lead to higher employee engagement, such as organizational climate, culture and leadership style.

\section{References}

Albrecht, S. L. and Andreetta, M., 2011. "The Influence of Empowering Leadership, Empowerment and Engagement on Affective Commitment and Turnover Intentions in Community Health Service Workers: Test of a Model", Leadership in Health Services, Vol. 24, Issue 3, pp. 228-237.

Anitha, J., 2014. "Determinants of Employee engagement and their impact on employee performance", International Journal of Productivity and Performance Management, Vol. 63, Issue 3, pp. 308-323.

Breevaart, K., Bakker, A., Hetland, J., Demerouti, E., Olsen, O. K. and Espevik, R., 2014. "Daily Transactional and Transformational Leadership and Daily Employee Engagement", Journal of Occupational and Organizational Psychology, Vol. 87, Issue 1, pp. 138-157.

Byrne, B. M., 1998. Structural Equation Modeling with LISREL, PRELIS and SIMPLIS: Basic Concepts, Applications and Programming. Mahwah, New Jersey: Lawrence Erlbaum Associates.

Christian, M. S., Garza, A. S. and Slaughter, J. E., 2011. "Work Engagement: A Quantitative Review and Test of Its Relations with Task and Contextual Performance", Personnel Psychology, Vol. 64, pp. 89-136.

Ehrhart, M. G., 2004. "Leadership and Procedural Justice Climate as Antecedents of Unit Level Organizational Citizenship Behavior", Personnel Psychology, Vol. 57, pp. 61-94.

Gagne, M. and Deci, E. L., 2014. "The History of Self-Determination Theory in Psychology and Management", In M. Gagne (Ed.), The Oxford Handbook of Work Engagement, Motivation, and SelfDetermination Theory (pp. 1-9). (Oxford Library of Psychology). United Kingdom: Oxford University Press.

Harter, J. K., Schmidt, F. L. and Hayes, T. L., 2002. "Business-Unit-Level Relationship Between Employee Satisfaction, Employee Engagement, and Business Outcomes: A Meta-Analysis", Journal of Applied Psychology, Vol. 87, Issue 2, pp. 268-279.

Huang, W. R. and Su, C. H., 2016. "The Mediating Role of Job Satisfaction in the Relationship between Job Training Satisfaction and Turnover Intentions", Industrial and Commercial Training, Vol. 48, Issue 1, pp. 42-52, https://doi.org/10.1108/ICT-04-2015-0029.

Joreskog, K. G. and Sorbom, D., 1984. Lisrel VI, Analysis of Linear Structural Relationships by Maximum Likelihood, Instrumental Variables, and Least Squares Methods. Mooresville, Indiana: Scientific Software.

Ling, W., Chen, L. and Wang, D., 1987. "CPM, A Scale to Measure CPM Leadership Behavior", Acta Psychologica Sinica, Vol. 2, pp. 199-207.

Ling, Y. H. and Ling, H., 2010. "How Intellectual Capital Management Affects Organizational Performances

- Intellectual Capital as Intervening Variable”, Journal of Human Resource Management, Taiwan, Vol. 10, Issue 1, pp. 1-27.

Lu, C. S. and Lin, C. C., 2014. "The Effect of Ethical Leadership and Ethical Climate on Employee Ethical Behavior in the International Port Context", Journal of Business Ethics, Vol. 124, pp. 209-223. 
Mencl, J., Wefald, A. J. and van Ittersum, K.W., 2016. "Transformational Leader Attributes: Interpersonal Skills, Engagement, and Well-being", Leadership and Organization Development Journal, Vol. 37, Issue 5, pp. 635-657.

Meng, B. and Han, H., 2014. "The Effects of Empowerment on Employee Psychological Outcomes in Upscale Hotels", Journal of Hospitality Marketing and Management, Vol. 23, pp. 218-237.

MacCallum, R.C., Browne, M.W. and Sugawara, H. M., 1996. "Power Analysis and Determination of Sample Size for Covariance Structure Modeling”, Psychological Methods, Vol. 1, Issue 2, pp. 130-49.

McKinney, K., 2004. "The Scholarship of Teaching and Learning: Past Lessons, Current Challenges, and Future Visions", To Improve the Academy: A Journal of Education Development, Vol. 22, Issue 1, pp. $3-19$.

Ministry of Education of the People's Republic of China (MOE), 2018. Number of Higher Education Institutions. Statistics Department, MOE China.

Misumi, J. and Peterson, M., 1985. "The Performance-Maintenance (PM) Theory of Leadership: Review of a Japanese Research Program", Administrative Science Quarterly, Vol. 30, Issue 2, pp.198-223. doi:10.2307/2393105.

Robinson, D., Perryman, S. and Hayday, S., 2004. The Drivers of Employee Engagement. Institute for Employment Studies, U.K.

Schaufeli, W. B., Salanova, M., Gonzalez-Roma, V. and Bakker, A. B., 2002. "The Measurement of Engagement and Burnout and A Confirmative Analytic Approach", Journal of Happiness Studies, Vol 3, pp. 71-92.

Schaufeli, W. B. and Bakker, A. B., 2003. Test Manual for the Utrecht Work Engagement Scale. Unpublished manuscript, Utrecht University, the Netherlands. Retrieved from http://www.schaufeli.com. Retrieved on April 1, 2018.

Steiger, J. H. and Lind, J. C., 1980. Statistically Based Tests for the Number of Common Factors. Paper presented at the annual meeting of the Psychometric Society, Iowa City, IA.

UNESCO Institute of Statistics, 2016. Data for Sustainable Development Goals. Available at http://uis. umescu.org, retrieved on April 20, 2018.

US Department of Education, 2016. National Centre for Education Statistics. Digest of Education Statistics 2015.

Vincent - -Höper, S., Muser, C. and Janneck, M., 2012. "Transformational Leadership, Work Engagement, and Occupational Success", Career Development International, Vol. 17, Issue 7, pp. 663-682, https: //doi.org/10.1108/13620431211283805.

Wang, D. S. and Hsieh, C. C., 2013. "The Effect of Authentic Leadership on Employee Trust and Employee Engagement", Social Behavior and Personality: An International Journal, Vol. 41, Issue 4, pp. 613-624. 